\title{
Development methodology to share vehicles optimizing the variability of the mileage
}

\section{Autores}

Luis E. Ramírez Polo, Alcides R. Santander-Mercado, Miguel A. Jimenez-Barros

\begin{abstract}
A simulation is a tool used to visualize the behaviors of a system, which will later help make decisions regarding how to handle the variables involved in the system, as well as the specific changes that have to be made. This study shows a case of vehicle allocation for different people within a company, evaluating methodologies, vehicle rotation to reduce the variance of the mileage and eliminating penalties with rental agencies for exceeding the permitted mileage. The paper shows a literature review of allocation models and similar studies, and later displays a detailed description of the problem, the variables that was used, the composition of the simulation and the optimization model that were generated, the results of the simulation, and finally, the findings of the research.
\end{abstract}

Palabras clave

Simulation, Optimization, Assignment problema, Vehicle share, Mileage limit 